\title{
El Patio Herreriano, escenario de un encuentro europeo en torno a los valores del coleccionismo artístico
}

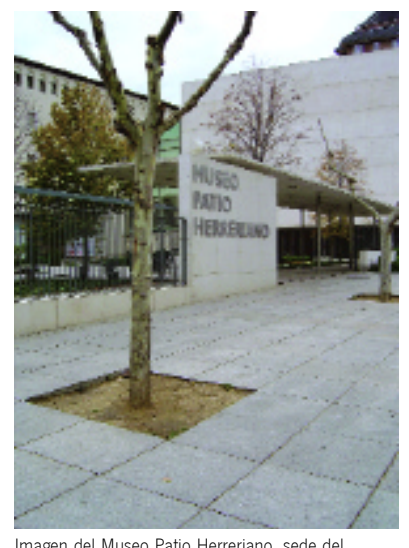

magen del Museo Patio Herreriano, sede de encuentro. Foto: Marta Garcia de Casasola
Organizadas por el Departamento de Historia del Arte de la Universidad de Valladolid, el Museo Patio Herreriano de Arte Contemporáneo Español de VaIladolid y la Carl Justi-Vereinigung, las jornadas del Simposio internacional Lo público y lo privado en el coleccionismo artístico. Ejemplos en España y Alemania desde el siglo XVIII hasta hoy (Valladolid, 21 al 23 de octubre de 2004) contaron con la participación de historiadores del arte, críticos y museólogos españoles, alemanes y de otros paises. Las diversas intervenciones tuvieron lugar en el marco de Museo Patio Herreriano, paradigma inusual de encuentro entre la iniciativa pública y la privada, marcado desde su origen con la existencia previa de una colección privada - la Colección Arte Contemporáneo -, puesta al servicio de la sociedad desde 2000. Estos y otros aspectos fueron puestos de relieve en la intervención de Olga Fernández López, Conservadora Jefe de este Museo.

El marco conceptual e histórico en el que se desarrollaron las participaciones fue el del análisis de la obra de arte y el de su colección entre los valores privados y públicos, siendo el punto de partida el cambio sustancial acontecido en el ámbito y funciones asignados al coleccionismo artístico a partir de la segunda mitad del siglo XVIII, momento en que muchas colecciones observaron su trasvase de lo privado a lo público con la creación de museos por parte de instituciones oficiales.

Surge así una problemática histórica de gran interés, pero también importante desde la perspectiva de lo actual, pues si, de un lado, pervivió, como pervive, el carácter privativo y subjetivo derivado de la posesión y disfrute de ciertas colecciones artísticas, de otro, el museo público vino a establecer la frontera más nítida y definitiva entre los usos privados y públicos existentes en el ámbito del coleccionismo privado anterior.

Sin embargo, este aspecto sancionador del Museo puede ser aparente. Es cierto que desde su nacimiento, el Museo público viene a establecer una suerte de consenso social respecto a una serie de valores y significados que los coleccionistas privados determinaron y determinan para con los objetos de sus colecciones. Valores que, no obstante su origen en una psicología individual, subjetiva, alcanzan a lo largo de la historia del coleccionismo una notable incidencia social y pública; y esto en una doble dimensión: por una parte intelectual, próxima al valor estético-contemplativo del objeto coleccionado, al sentido formativo, erudito, etc. Por otra parte, material (prestigio social, político, económico, etc.). Al respecto, sabemos que en numerosas ocasiones las colecciones privadas observaron y observan aspectos públicos, así, los de- seos personales de permanencia en el tiempo de la colección y su apertura al público, apoyados en razones ideológicas, de prestigio, investigadoras, pedagógicas, etc.

Pero también es cierto que los Museos públicos en la incorporación de colecciones privadas a sus fondos se hallan obligados a asumir, por motivaciones económicas, politicas o sociales, las dimensiones materiales características de las mismas (gustos subjetivos, prestigio, etc.). Esto frente a la tradicional filtración objetiva y homogeneización de objetos y espacios practicadas por estas Instituciones respecto a planteamientos individuales.

La amplitud del tema elegido obliga a un proceso de sintesis y fijación de un marco geográfico y temporal (Alemania-España; siglos XVIII-XXI) sin desdeñar puentes a épocas anteriores y a otros países.

Abrió el turno de intervenciones Anne Marie Freybourg, historiadora del arte alemana y responsable de numerosos proyectos sobre arte contemporáneo, algunos en colaboración con Harald Szeeman. Ferybourg abogó por el retorno a la tradicional posición normativa de los museos respecto a la fijación de valores estéticos objetivos frente a la subjetividad de gustos y significados de las colecciones privadas.

Profundizó en éste y otros aspectos Michael Scholz-Hänsel, historiador del arte y profesor de la Universidad de Leipzig, al socaire de la apertura institucional en Berlín de dos colecciones privadas de arte moderno y contemporáneo: la de Heinz Berggruen y la de C.F. Flick, y de las verdaderas razones - políticas o estéticas - de su integración en el panorama artístico de la capital alemana.

A partir de ahí, las jornadas discurrieron por cauces cronológicos, seguidas de intensos y esclarecedores debates. Marino Viganò, de la Universidad de Milán y especialista en arquitectura militar, esbozó los significados y valores teórico-formativos, descriptivos, prácticos y de prestigio (metáforas del poder) encarnados por las colecciones de modelos de plazas fuertes de los Borbones españoles, franceses y napolitanos del siglo XVIII.

Pavel Stepánek, de la Universidad Palackého de Olomuc y de la Carolina de Praga, reflexionó acerca del origen y carácter de la Galería Nacional de Praga, primera colección pública del reino de Bohemia en el siglo XVIII.

Matthias Weniger, Conservador de Pintura y Escultura anterior a 1550 en el Bayerisches Nationalmuseum de Munich, habló sobre las cir- 

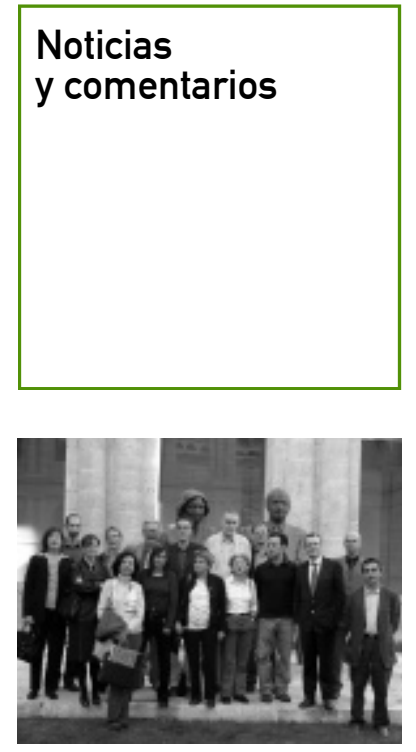

Participantes del Simposium cunstancias de la incorporación en el siglo XIX de obras de pintura española del siglo XVII - Velázquez, Murillo, Zurbarán, Valdés Leal, etc. - a la Gemäldegalerie de Dresde, lo que determinó el establecimiento de una colección sistemática de pintura religiosa católica española en una ciudad hasta hoy considerada como bastión de la iglesia protestante. La reflexión de María de los Santos García Felguera, de la Universidad Complutense de Madrid, versó sobre la vida, gusto y actividad coleccionista - Van Dyck, Watteau, Murillo, etc. - de la Condesa de Verrue en el siglo XVIII, mientras que Carlos Chocarro Bujanda, profesor de Historia del Arte y de la Arquitectura de la Universidad de Navarra, profundizó en el papel institucional jugado por la Academia de Bellas Artes de San Fernando y sus colecciones de escultura desde el punto de vista de su conservación, de su instrumentalización política y carácter formativo.

Teresa Posada Kubissa, Conservadora del Departamento de Pintura Flamenca y Holandesa del siglo XVII del Museo del Prado, centró su intervención en la evolución de la Colección PastranaInfantado desde sus origenes en 1630 hasta su desaparición en 1841 y llegada de parte de las mismas - bocetos de Rubens para la Torre de la Parada - al Museo del Prado.

Sven Kuhrau, Gastprofessor en la Universität der Künste de Berlín, habló de las motivaciones existentes en el compromiso público adquirido por los coleccionistas privados del Berlín de la segunda mitad del siglo XIX.

La Conservadora del Museo Lázaro Galdiano de Madrid, Amparo López Redondo, desarrolló su ponencia en torno a la reciente remodelación acontecida en este Museo, que ha apostado por una lectura ordenada de sus colecciones en detrimento de la tradicional identidad de vivienda de un coleccionista, en este caso Lázaro Galdiano, uno de los paradigmas en lo que a protección del Patrimonio Histórico Español se refiere.

Ángel Azpeitia Burgos, de la Universidad de Zaragoza y asesor destacado del proyecto museológico de la Colección Beulas, núcleo inicial del futuro Museo-Centro Aragonés de Arte Contemporáneo para el que Rafael Moneo ha diseñado el edificio, trató de las peculiares circunstancias que han rodeado tal fundación, cuyo origen queda constituido por el legado al Gobierno de Aragón de las colecciones de pintura contemporánea del pintor José Beulas bajo la condición de su institucionalización.

El argumento sostenido por María Bolaños Atienza, de la Universidad de Valladolid, en su intervención fue el de considerar el gesto del artista al colgar su obra en el ámbito privado del taller (Matisse, Brancusi, Miró, etc.) como un peculiar in- tento de procurar una relación visual y una defensa de la presencia existencial de su obra, pero también una cierta sugerencia del modo en que le gustaría ver expuesta su producción, así como una manera de concebir el proceso creativo.

Por su parte, Michael Nungesser, historiador y crítico de arte berlinés, expuso las peculiaridades de una institución como la del Museo Vostell Malpartida de Cáceres, uno de los primeros museos de arte contemporáneo fundados tras la muerte de Franco, fundado por el artista alemán Wolf Vostell a partir de su propia producción y de colecciones tan representativas del ámbito internacional como las del Movimiento Fluxus o la de artistas conceptuales de muy diversos ámbitos.

David Sánchez Cano, historiador de la Technische Universität de Berlin y miembro del Comité Directivo de la Carl Justi-Vereinigung, disertó acerca del coleccionismo de fotografías en España y de la transformación de archivos fotográficos personales, carentes de un estricto sentido de colección, en colecciones públicas; dinámica en la que la Colección Castellano, de la Biblioteca Nacional, aún sin catalogar e investigar, constituye una excepción.

Excepción al marco geográfico fijado en el Simposio fue la intervención de Ana Garduño Ortega, del Centro Nacional de Información, Documentación e Investigación en Artes Plásticas del Instituto Nacional de Bellas Artes de México. La investigadora habló del difícil proceso de institucionalización de la colección del médico mexicano Alvar Carrillo Gil (1898-1974).

Finalmente, la profesora Carmen Bernárdez Sanchís, de la Universidad Complutense de Madrid, comisaria de numerosas exposiciones de arte contemporáneo y con larga dedicación a la documentación de colecciones de este ámbito (Colección Arte Contemporáneo, núcleo del Museo Patio Herreriano), cerró el ciclo de participaciones del Simposio con el planteamiento de una serie de cuestiones relativas a la proliferación de museos, centros y colecciones de arte contemporáneo en España; así, el papel desempeñado o que deberían desempeñar estas instituciones en la sociedad actual y los diversos modelos establecidos en las mismas respecto al relato de la historia del arte. Modelos adscritos, bien al aún vigente modo lineal de las vanguardias (el planteado por Alfred Barr para el MOMA), bien a tendencias menos hegemónicas y más comprometidas con la producción artística actual.

José Luis Cano de Gardoqui García

Profesor de la Universidad de Valladolid y Coordinador del Simposio 